\title{
Iron Contamination Mechanism and Reaction Performance Research on FCC Catalyst
}

\author{
Zhaoyong Liu, ${ }^{1,2}$ Zhongdong Zhang, $^{1,2}$ Pusheng Liu, ${ }^{2}$ Jianing Zhai, ${ }^{2}$ and Chaohe Yang ${ }^{1}$ \\ ${ }^{1}$ State Key Lab of Heavy Oil Processing, China University of Petroleum, Qingdao, Shandong 266555, China \\ ${ }^{2}$ Lanzhou Petrochemical Research Institute, CNPC, Lanzhou, Gansu 730060, China \\ Correspondence should be addressed to Zhaoyong Liu; lzy0539@126.com
}

Received 7 May 2015; Accepted 25 June 2015

Academic Editor: Zhongwei Zhu

Copyright (c) 2015 Zhaoyong Liu et al. This is an open access article distributed under the Creative Commons Attribution License, which permits unrestricted use, distribution, and reproduction in any medium, provided the original work is properly cited.

\begin{abstract}
FCC (Fluid Catalytic Cracking) catalyst iron poisoning would not only influence units' product slate; when the poisoning is serious, it could also jeopardize FCC catalysts' fluidization in reaction-regeneration system and further cause bad influences on units' stable operation. Under catalytic cracking reaction conditions, large amount of iron nanonodules is formed on the seriously iron contaminated catalyst due to exothermic reaction. These nodules intensify the attrition between catalyst particles and generate plenty of fines which severely influence units' smooth running. A dense layer could be formed on the catalysts' surface after iron contamination and the dense layer stops reactants to diffuse to inner structures of catalyst. This causes extremely negative effects on catalyst's heavy oil conversion ability and could greatly cut down gasoline yield while increasing yields of dry gas, coke, and slurry largely. Research shows that catalyst's reaction performance would be severely deteriorated when iron content in E-cat (equilibrium catalyst) exceeds $8000 \mu \mathrm{g} / \mathrm{g}$.
\end{abstract}

\section{Introduction}

Resid oil, especially Vacuum Resid oil, is an intermediate product with the least value in refineries. Refineries' economic profits are largely dependent on VR's (Vacuum Resid oil) conversion scheme and deepness. RFCC (Resid Fluid Catalytic Cracking) process has advantages of high processing capacity, good application ability, and high economic benefits which are very suitable for our country's current secondary processing situation in petroleum industry. Therefore, RFCC is an important way of VR conversion in order to improve refineries' economic profits and the research and development of RFCC catalyst are one of the key technologies.

There are large amounts of heavy metal such as vanadium [1], nickel [2], and iron [3] and these elements have strong poisoning effects on catalyst. When nanovanadium is deposited on catalyst surface, the vanadic acid which is similar to phosphoric acid that is formed by redox reaction would destroy zeolite's crystal structure and lead to low catalyst conversion and bad product distribution. Different from vanadium poisoning, when nickel is deposited on catalyst surface with a large quantity, nanonickel's dehydrogenation activity would lead to increasing yields of dry gas and coke [2]. As to iron poisoning, except for iron in feedstock, the carried iron during crude oil's transportation could also lead to catalyst's iron poisoning. In recent years, there are sometimes iron poisoning phenomena that occurred in domestic refineries [3-12]. But, unfortunately, our researchers have not had profound understanding on catalyst iron poisoning. Iron poisoning at low concentration has mild poisoning effect on catalyst, but, with more and more iron deposits on catalyst significantly, catalysts' reaction performance would be deteriorated greatly, especially for heavy oil conversion activity.

This paper discusses iron's poisoning effect on catalysts from the angle of practical industrial production and comes up with simple classification on catalyst iron ions poisoning level. 


\section{Experiment}

2.1. Equivalent-Volume Impregnation on Catalyst. First, a certain amount of sample is weighed and placed in beaker, and then deionized water is added dropwise while stirring with glass stick. The amount of water added is recorded when thixotropy of catalyst is observed. The nickel ion contamination sample's preparation is the same with vanadium ion contamination sample's preparation and the nickel ion used is nickel nitrate with $9 \mathrm{H}_{2} \mathrm{O}$.

\subsection{Preparation of Model Catalyst. The preparation process} of model catalyst is as follows.

First Kaolin-clay (Suzhou Kaolin company) is mixed with water. When the system is thoroughly dispersed, alumina binder (Shandong Alumina company) and relevant zeolite (Lanzhou Petrochemical company) are added into system in order. After stirring for an hour, the mixture is spray dried and shaped into semifinished catalyst. After calcinations and filtration wash, the finished catalyst sample is prepared.

2.3. Characterization. Particle size and crystal morphology of the samples were examined with a scanning electron microscopy (SEM) and energy dispersive spectrometer (EDS), which was carried on S4800. X-ray fluorescence spectroscopy (Axios) was used to analyze the iron content in all the samples.

2.4. Advanced Cracking Evaluation (ACE). Advanced Cracking Evaluation (ACE) is developed by KTI Technology company, USA. The device is equipped with a single reactor and both reaction and regeneration process take place in the same reactor. The device has a small size, low consumption of raw material, and a high automatic level and it is very suitable for labs to do research on catalyst's performance and selectivity on catalyst formula.

In this experiment, the weighed, unevaluated catalyst is injected into ACE unit's fluidization catalytic cracking reactor through ACE unit's experimental injection system; feedstock is also injected into reactor through oil pump system with a certain quantity. The catalyst and feedstock perform catalytic cracking reaction under setting evaluation parameter. The reacted oil gas is stripped with nitrogen and gasoline, diesel, heavy oil, and other liquid products are collected in condensing collector while dry gas, LPG, and other gas products are collected in gas collector. The composition analysis is done according to SH/T0558 method with simulated distillation gas chromatography and UOP Method 539 with refinery gas analysis gas chromatography, respectively. After stripping, the catalyst in reactor is regenerated with air, the $\mathrm{CO}$ in the regenerating flue gas is converted to $\mathrm{CO}_{2}$ with reforming furnace, and eventually the coke value is tested by in situ FTIR $\mathrm{CO}_{2}$ analyzer. After the regeneration, the reactor is cooled and the catalyst in reactor is automatically unloaded to wasted catalyst can. According to the weight of each component, the product slates can be calculated and FCC catalyst's selectivity and its reacting rules can be obtained and then FCC catalyst's cracking performance is evaluated.

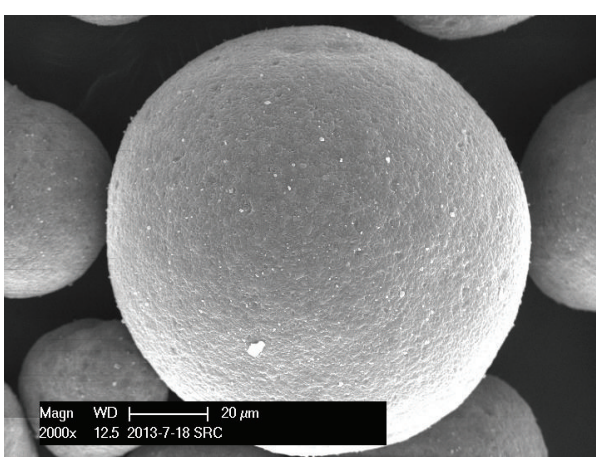

(a)

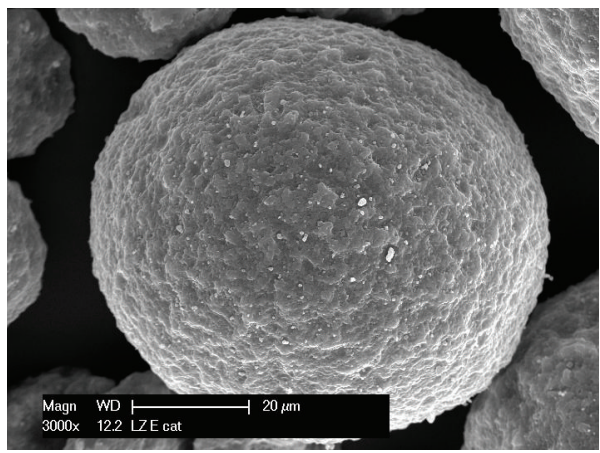

(b)

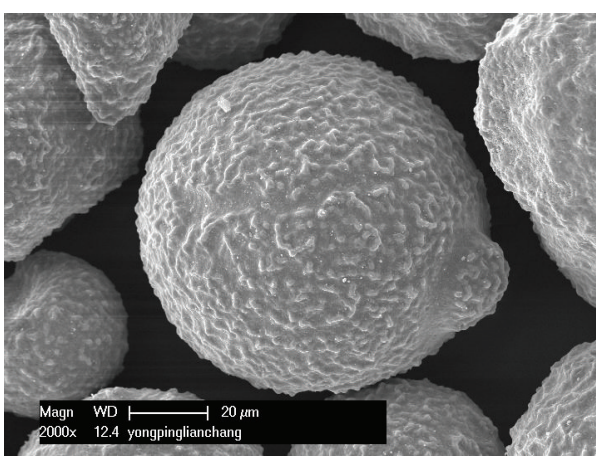

(c)

FIgURE 1: SEM images of E-cat iron poisoning ((a) low iron; (b) moderate iron; (c) high iron).

\section{Conclusion and Discussion}

3.1. Iron Poisoning's Influence on E-Cat's Morphology. Lab research shows that catalyst iron poisoning would cause severe damage to catalyst particle and its spherical shape. Figure 1 shows SEM (scanning electron microscope) pictures of equilibrium catalysts with different iron poisoning levels. In Figure 1, when E-cat iron content is relatively low (around $4000 \mu \mathrm{g} / \mathrm{g}$ ), the catalysts' surface is smooth; with the increase of iron concentration (around $6000 \mu \mathrm{g} / \mathrm{g}$ ), the E-cat's surface becomes apparently less smooth; after the iron concentration further increases to around $8000 \mu \mathrm{g} / \mathrm{g}$, many fissures and nodules are formed on the surface of E-cats. These E-cats 


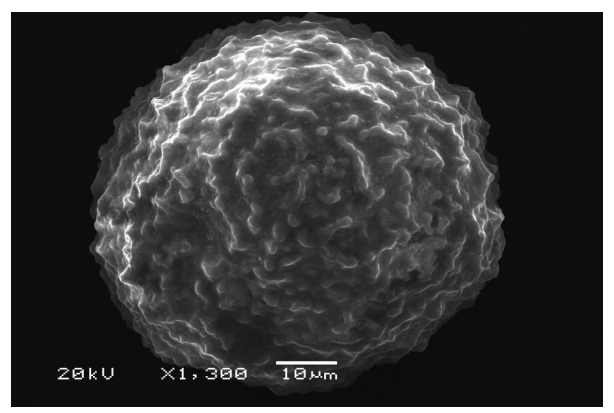

(a)

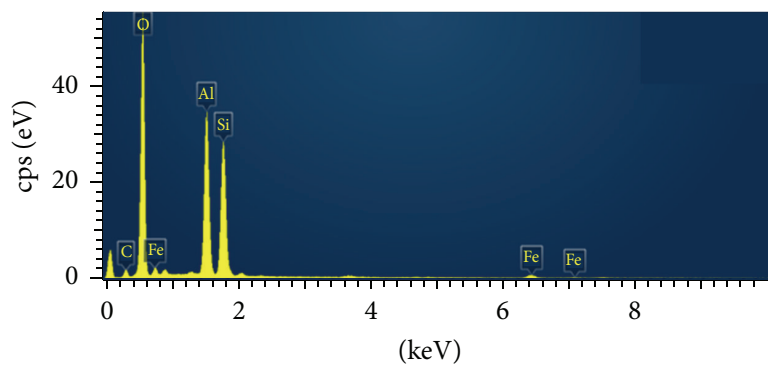

(b)

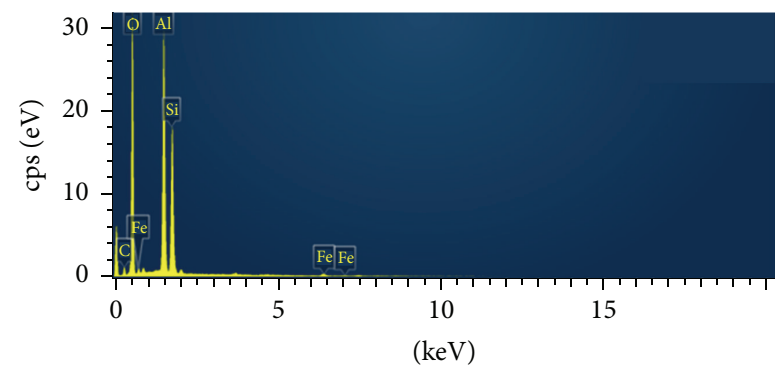

(c)

FIGURE 2: Distributions of Fe on the surface of E-catalyst with (a) catalyst with high iron content; (b) element analysis of iron nodule; (c) element analysis of smooth surface.

with rough surface rub with each other and generate large quantity of fines in catalysts' reaction-regeneration system. The lab research further analyzed iron distribution on the surface of E-cats with high iron poisoning level. The research found out that the nodules on catalysts' surface have higher iron content and the tested E-cat sample has the iron content as high as $13200 \mu \mathrm{g} / \mathrm{g}$. The area that has no nodules has lower iron content of $7300 \mu \mathrm{g} / \mathrm{g}$. The result is shown in Figure 2 . According to iron content of E-cat, we denote them as E-catl $(4000 \mu \mathrm{g} / \mathrm{g})$, E-cat2 $(6000 \mu \mathrm{g} / \mathrm{g})$, and E-cat3 $(8000 \mu \mathrm{g} / \mathrm{g})$.

\subsection{Criterion of FCC Catalysts' Poisoning Level. The lab} made comparison evaluations on reaction performances of catalysts with different iron poisoning levels with ACE units. Figure 3 is the alteration curve of catalyst's conversion rate and heavy oil yield correlated with catalyst iron poisoning level. Figure 4 shows that when catalysts' iron poisoning is low, both bottom yield and conversion rate are, respectively, increasing and decreasing at a moderate speed; when E-cat has higher level of iron poisoning (around $8000 \mu \mathrm{g} / \mathrm{g}$ ), both bottom yield and conversion rate are, respectively, increasing and decreasing quickly.

In catalytic cracking reaction process, LCO is not only the heavy oil molecules' cracking product, but also the catalysts' cracking raw material. Figure 4 shows alteration trend of LPG and gasoline's yield along with LCO and bottom yield correlated to catalysts' iron poisoning. In Figure 5, we could see that, with the catalysts' iron poisoning level increasing,

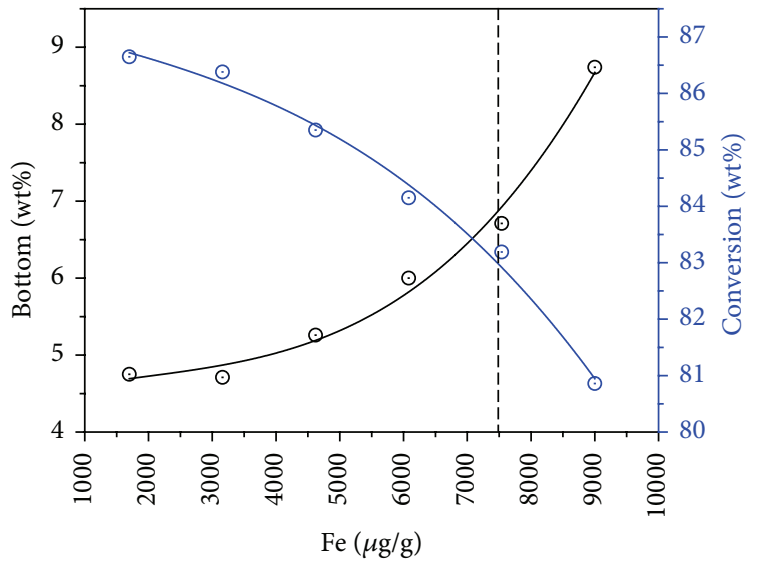

FIGURE 3: Alteration curves of catalyst's conversion rate and heavy oil yield correlated with catalyst iron poisoning level.

LPG and gasoline's yields decreased significantly and LCO and bottom's yields increased obviously. Similar to the trend of conversion rate and bottom yield's change correlated to catalyst iron content, when catalyst has higher iron content (around $8000 \mu \mathrm{g} / \mathrm{g}$ ), LCO and bottom's yields increase rapidly while LPG and gasoline's yields decrease quickly.

Figure 5 shows that, with the increase in catalyst iron content, the dry gas and coke's yields are also increased significantly. Due to iron ions' severe damage to catalysts' 


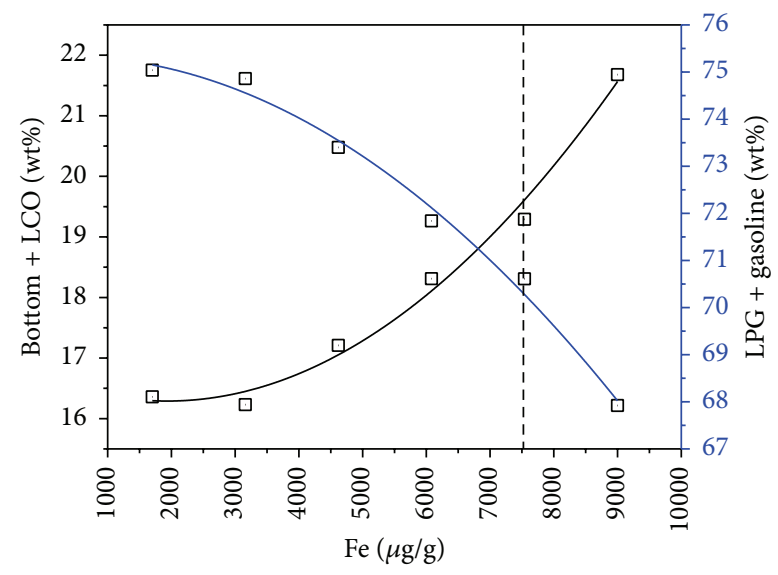

FIGURE 4: Alteration trend of LPG and gasoline's yield along with LCO and bottom yield correlated to catalysts' iron poisoning.

TABLE 1: ACE results of E-catalysts.

\begin{tabular}{lccc}
\hline Items & E-cat1 & E-cat2 & E-cat3 \\
\hline Dry gas/wt\% & 2.35 & 2.64 & 3.13 \\
LPG/wt\% & 17.55 & 16.36 & 14.64 \\
Gasoline/wt\% & 47.82 & 46.85 & 43.76 \\
LCO/wt\% & 16.13 & 16.5 & 16.95 \\
Slurry/wt\% & 8.46 & 9.35 & 12.82 \\
Coke/wt\% & 7.69 & 8.30 & 8.70 \\
\hline
\end{tabular}

surface, thermal cracking takes place largely and leads to increasing in dry gas and coke's yields. Besides, similar to nickel ions, iron also has high dehydrogenation activity. Therefore, when E-cat has high iron poisoning level, iron ions' dehydrogenation activity will also lead to increasing in dry gas and coke's yields.

Research also found that when catalyst has high iron content (around $8000 \mu \mathrm{g} / \mathrm{g}$ ), catalysts' color will turn red, which has great difference with regular catalysts. Figure 6 shows the appearances of the same catalyst that applied in different refineries. From catalysts' appearances we could see that the HB E-cat shows obvious red color due to its high iron content which is more than $8000 \mu \mathrm{g} / \mathrm{g}$.

\subsection{Reaction Performances of E-Cats with Different Iron} Poisoning Levels. Table 1 lists ACE unit evaluation results of three E-cats with different iron poisoning levels. The Ecats E-cat1, E-cat2, and E-cat3 have gradually increasing iron poisoning levels. From Table 1, we could see that E-cat3 has the highest dry gas and coke yields and lowest conversion rate and light oil yield due to its highest iron poisoning level. It is consistent with the evaluation results of tests on E-cats with different iron poisoning levels; when catalyst has high iron content, its reaction performance degenerates quickly and target product's yield significantly decreases.

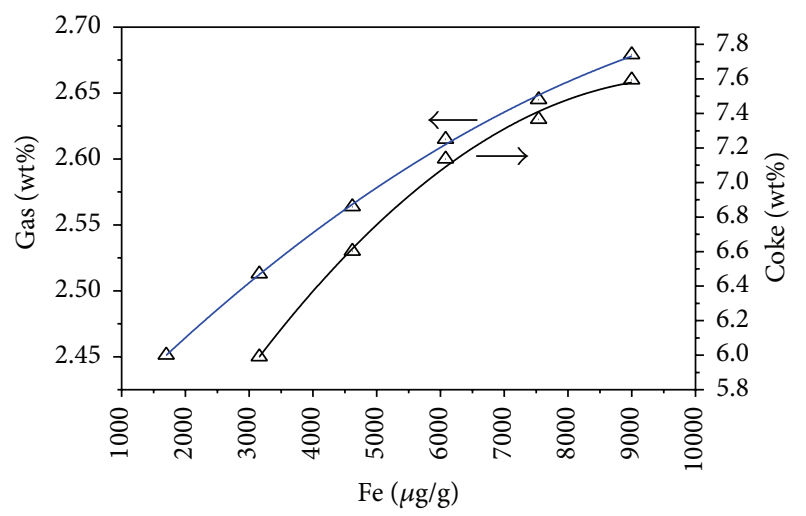

FIGURE 5: Fe dependence of gas and coke yields for the catalysts.

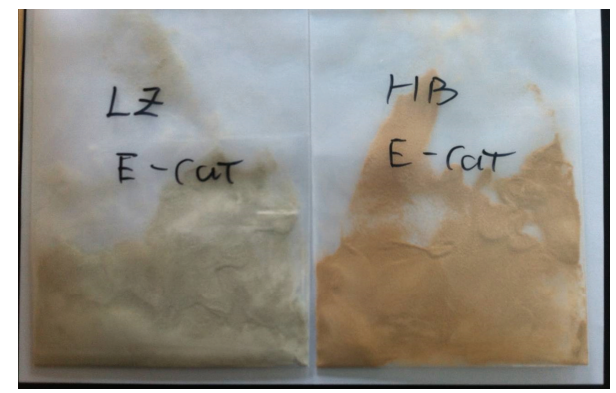

FIGURE 6: Color of E-catalysts with varying iron content.

E-cats' iron poisoning happens occasionally in refinery. When iron ions deposit on catalysts' surface at a large quantity, the low melting point eutectic formed by iron and catalyst particles would cover catalysts' surface and block feedstock molecules' diffusion to catalysts' inner pores, which leads to lower feedstock cracking ability and target products yield. Besides, catalyst iron poisoning would lead to rough catalyst surface. Rough catalysts collide with each other and generate large quantities of fines that reduce catalysts' utilization efficiency, increase processing costs, and even cause E-cats' fluidization problems in the reactor-regeneration system.

3.4. Iron Poisoning Mechanism. Iron is a transition metal that can have a devastating effect on catalyst performance [7$10,13]$. Like vanadium, iron can form a eutectic. However, while vanadium can be found throughout the whole catalyst particle, iron typically sticks to the external surface. The appearance of the FCC catalyst changes from smooth spherical particles into particles with a bumpy nodularized surface (Figures 1 and 2). Iron deposited on the catalyst agglomerates into small crystals of magnetite at the catalyst surface. The nodules at the surface are formed by matrix capped with magnetite. The magnetite crystallites readily react with $\mathrm{H}_{2} \mathrm{~S}$ in the riser forming iron sulfide. In the regenerator, iron sulfide is reoxidized to magnetite (liberating the $\mathrm{S}$ as $\mathrm{SO}_{2}$ ). Oxidation of iron sulfide not only is strongly exothermic 

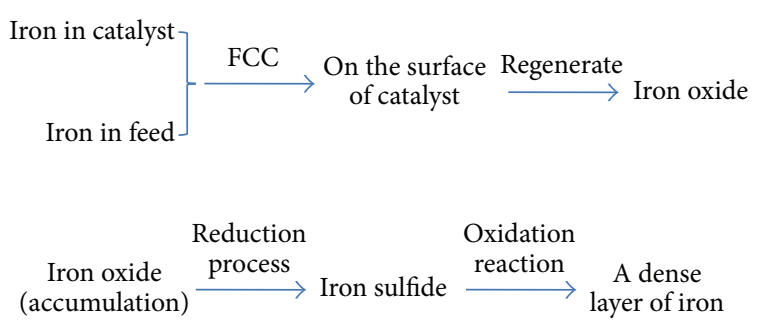

FIGURE 7: Iron poisoning process.

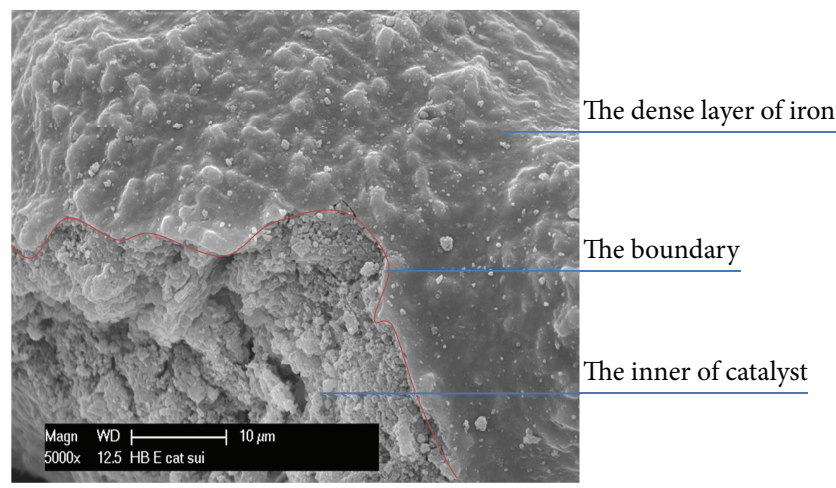

FIGURE 8: SEM image of E-catalyst with high iron content.

but also proceeds at lightning speed as it is catalyzed by its own product, iron oxide. The huge amount of heat unleashed in a very brief time melts the surrounding matrix. Where vanadium "only" forms a eutectic, iron forms a eutectic and infuses sufficient heat to melt a layer of the silica-alumina matrix at the particle surface up to several microns deep. The result is the formation of a dense layer (iron oxide), typically a few microns in depth (Figure 8). The zeolite and matrix at the core of the catalyst particle are unaffected by iron, but they are no longer available for cracking due to the diffusion barrier formed at the surface. The iron poisoning process is shown in Figure 7.

\section{Conclusion}

Catalyst iron poisoning will not only affect FCC unit's product slate, but also cause catalyst fluidization problem in the reactor-regenerator system when situation is serious and further jeopardize unit's stable operation. Therefore, iron poisoning should be paid high attention.

(a) Under catalytic cracking condition, catalyst with high iron poisoning level has large quantities of nodules on the surface due to exothermic reaction. E-cats with rough surface collide with each other and generate large quantity of fines that jeopardize FCC unit's stable operation.

(b) After catalyst iron poisoning, a layer of dense material is formed on the surface of catalyst. This layer blocks feedstock molecules' diffusion to catalysts' inner pores, which leads to significant decrease on gasoline yield and great increase on dry gas and coke's yields. Research shows that when E-cat's iron poisoning level is above $8000 \mu \mathrm{g} / \mathrm{g}$, catalysts' reacting performance would dramatically degenerate.

\section{Conflict of Interests}

The authors declare that there is no conflict of interests regarding the publication of this paper.

\section{Acknowledgment}

The authors thank the Ministry of Science and Technology Management of PetroChina for providing financial support.

\section{References}

[1] T. Li, X. Wang, Y. Zhu, and Z. Wang, “The valence state of vanadium and its poisonous effect on catalysts during catalytic cracking process," Petroleum Processing and Petrochemicals, vol. 44, no. 2, pp. 1-7, 2013.

[2] T. Ye and H. Pan, "The mechanisms of pollution of Ni and V deposited on FCC catalysts and its passivation," Petro, vol. 6, no. 4, pp. 226-228, 1999.

[3] Q.-S. Du, Y.-X. Zhu, W. Lin, and J. Long, "Studies of the iron poison on the FCC catalysts," Acta Petrolei Sinica, vol. 23, no. 3, pp. 37-40, 2007.

[4] A. M. Brass and J. Chene, "Influence of deformation on the hydrogen behavior in iron and nickel base alloys: a review of experimental data," Materials Science and Engineering A, vol. 242, no. 1-2, pp. 210-221, 1998.

[5] B. V. Vora, "Development of dehydrogenation catalysts and processes," Topics in Catalysis, vol. 55, no. 19-20, pp. 1297-1308, 2012.

[6] H. H. Gao, G. Wang, C. M. Xu, and J. Gao, "Eight-lump kinetic modeling of vacuum residue catalytic cracking in an independent fluid bed reactor," Energy and Fuels, vol. 28, no. 10, pp. 6554-6562, 2014.

[7] L. Shi, L. T. Bi, and Y. Yao, "Influence of iron on catalytic cracking catalyst," Qilu Petrochemical Technology, vol. 40, no. 1, pp. 50-53, 2012.

[8] Y. Mathieu, A. Corma, M. Echard, and M. Bories, "Single and combined Fluidized Catalytic Cracking (FCC) catalyst deactivation by iron and calcium metal-organic contaminants," Applied Catalysis A: General, vol. 469, pp. 451-465, 2014.

[9] D. Wallenstein, D. Farmer, J. Knoell, C. M. Fougret, and S. Brandt, "Progress in the deactivation of metals contaminated FCC catalysts by a novel catalyst metallation method," Applied Catalysis A: General, vol. 462-463, pp. 91-99, 2013.

[10] H. S. Cerqueira, G. Caeiro, L. Costa, and F. Ramôa Ribeiro, "Deactivation of FCC catalysts," Journal of Molecular Catalysis A: Chemical, vol. 292, no. 1-2, pp. 1-13, 2008.

[11] Y. Lü, "Poisoning of FCC catalyst by iron and countermeasures," Petroleum Refinery Engineering, vol. 32, no. 3, pp. 42-46, 2002. 
[12] J. Shen, H. Liu, and X. Zhou, "Influence of Fe in feedstock on RFCC reaction," Petroleum Refinery Engineering, vol. 34, no. 9, pp. 34-37, 2004.

[13] T. Hochheiser, Y. Tang, M. Allahverdi, and B. De Graaf, "FCC additive improves residue processing economics with high iron feeds," Tech. Rep. AM-14-27, AFPM, 2014. 

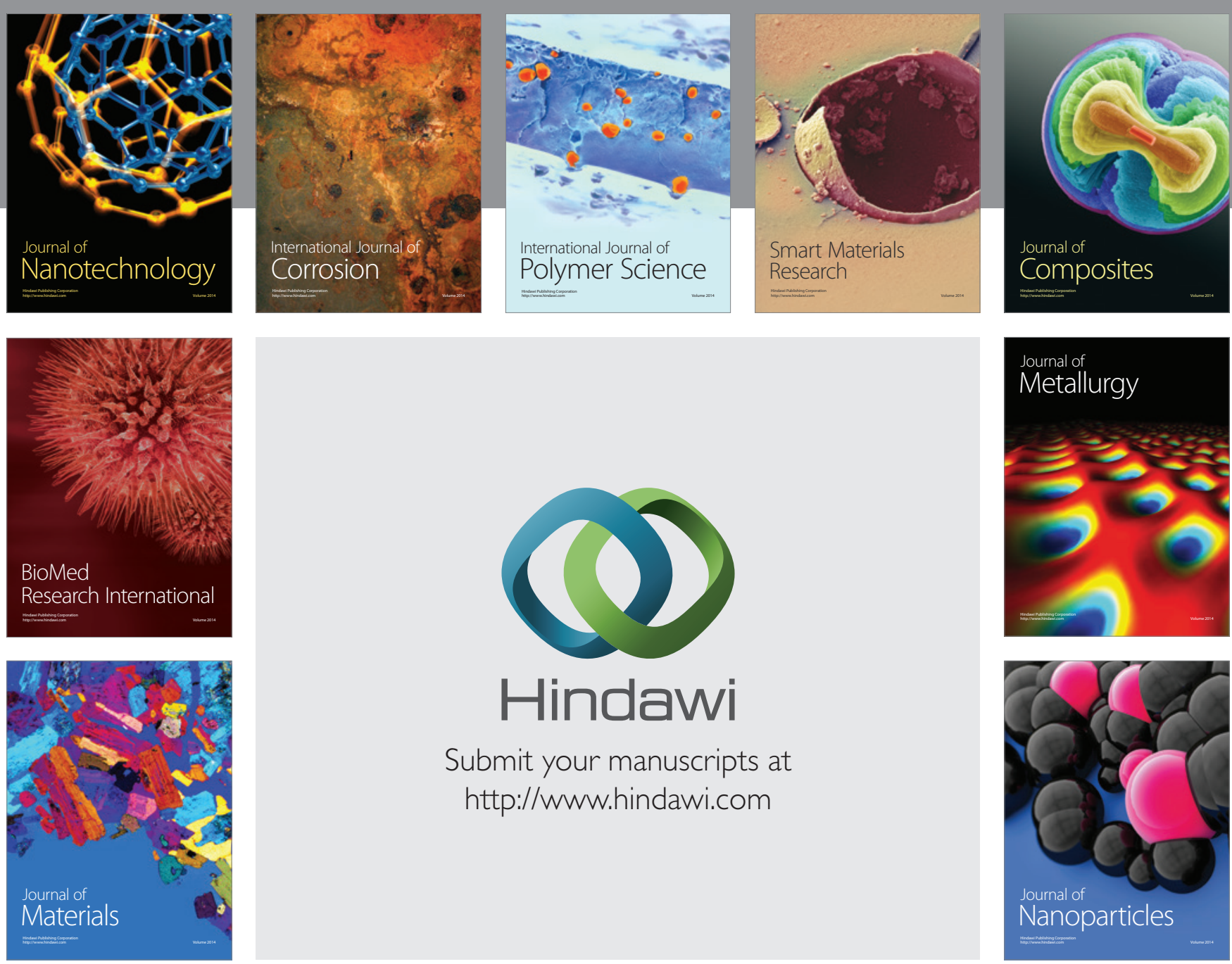

Submit your manuscripts at http://www.hindawi.com
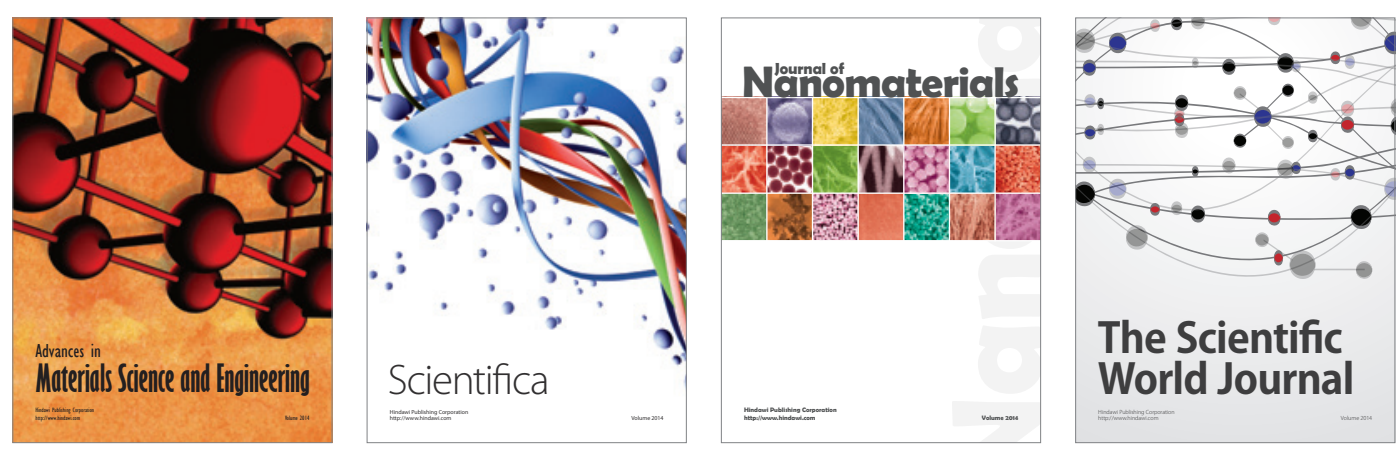

\section{The Scientific World Journal}
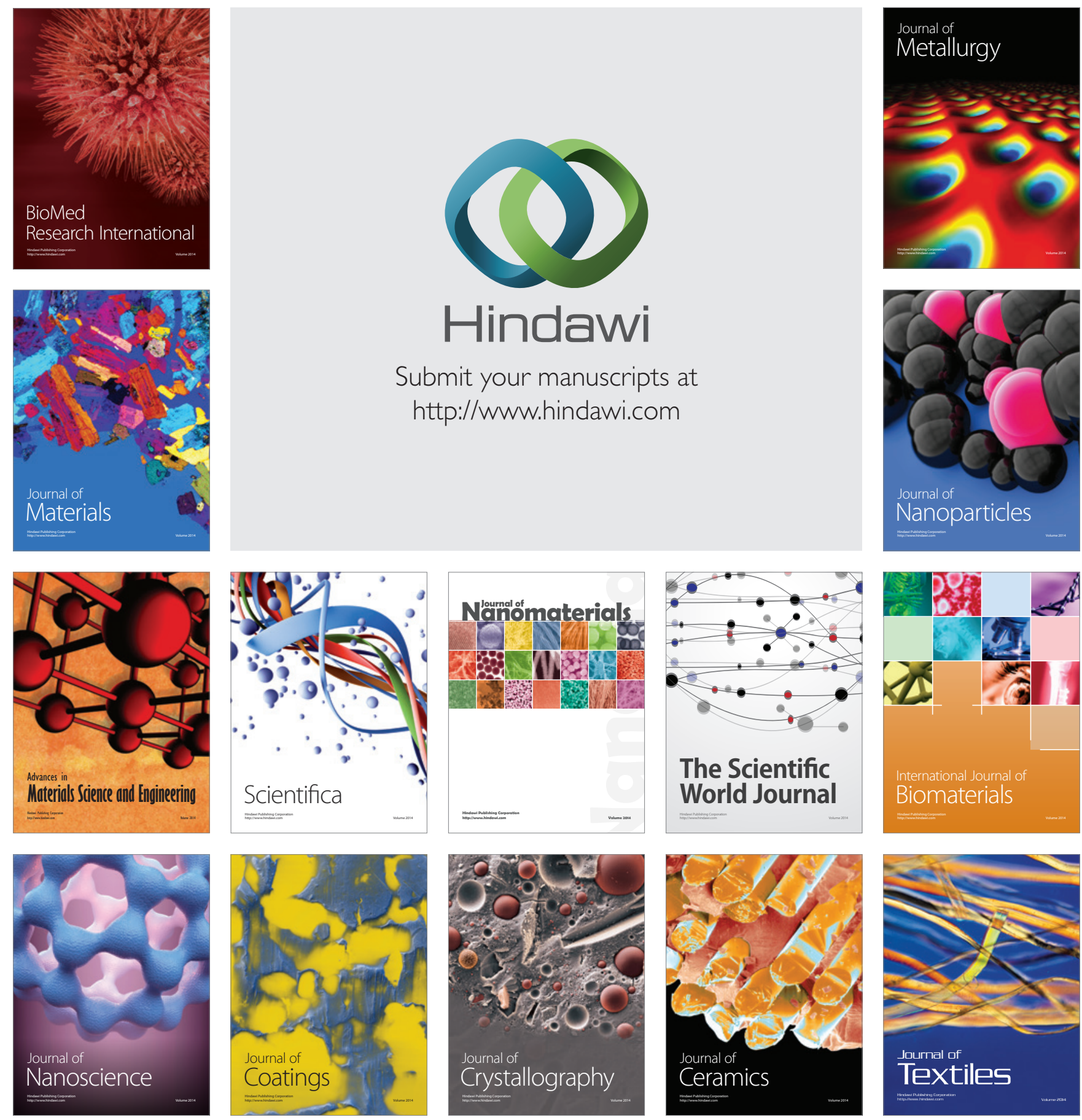